\title{
Salvage Robotic Prostatectomy and High Risk Disease: What Else Can We Do?
}

\author{
Goonewardene SS ${ }^{1 *}$, Persad $\mathrm{R}^{2}$ and Gillatt $\mathrm{D}^{2}$ \\ ${ }^{1}$ The Royal Free Hospital and UCL Medical School, UK \\ ${ }^{2}$ The Royal Marsden, UK
}

Submission: May 27, 2016; Published: October 12, 2016

*Corresponding author: Goonewardene SS, The Royal Free Hospital and UCL Medical School, London, UK

\begin{abstract}
Salvage radical prostatectomy (sralp) is known for managing more high risk disease. This is a treatment option for biochemical recurrence in prostate cancer [1]. This is an uncommonly performed procedure, which may be technically challenging [1]. Failure of non-surgical primary treatment for localized disease has rates ranging from $20 \%$ to $60 \%$ [2]. Very often, during salvage procedures, due to the loss of tissue planes and fibrosis, more extensive dissection is required. This leads to a higher rate of complications. Given the advances within robotics, this next question should robotic surgery be considered for high risk prostate cancer and what are the technical tips?
\end{abstract}

Keywords: Robotics; Surgery; Salvage therapy; Prostatectomy; High risk

\section{Letter to Editor}

Salvage radical prostatectomy is a technically challenging procedure that is associated with high complication rates for rectal injury, urinary leak an automatics structure and incontinence [3]. There can be extensive extra-prostatic fibrosis leading to distorted anatomy and difficulty with tissue-planes [4]. Robotic-assisted salvage radical prostatectomy is not widely performed. This has specific advantages including $3 \mathrm{D}$ visualization of tissue planes rather than feel, blood loss and a more secure an astomosis [4]. If the degree of dissection is less, outcomes are better.

It has also previously been shown, with multivariable analysis, D'Amico risk groups or pathologic Gleason grade, stage, and margins were the strongest predictors of biochemical recurrence in salvage therapy [5]. Detectable PSAs and high risk disease were independent predictors of receipt of salvage therapy [6]. Persistent disease signals the risk of progression likely requiring early salvage treatment [7]. However, if this is detected early, and disease is localized, outcomes will be better.

Part of the explanation for the rapid uptake of robotic surgery is the gentler learning curve compared with laparoscopic radical prostatectomy. Even though robotic, salvage surgery still has potential difficulties, these can be overcome with the robotic platform [8]. Voiding complications while on the steepest part of the learning curve is crucial to overcome [8]. Urinary leak identified by postoperative cystogram was common [39\%] [8]. This is comparable to other robotic series. Although some patients had limited follow-up, 6 [33\%] were continent and 67\% were free of biochemical progression.

Many sralp patients have localized disease recurrence and therefore potentially curable disease [2]. The key to decreased morbidity sralp outcomes are to have experienced centers and fellowship training [2]. The robotic surgery curriculum is welcomed as part of this. These centres have demonstrated the advantages of the robotic platform in the performance of salvage radical prostatectomy. This includes decreased blood loss, short length of stay and improved hepatic feedback. This was confirmed with a decreasing positive surgical margin rate with each consecutive group of 50 cases, including pT3 and highrisk patients [9]. The 3-year, 5-year, and 7-year BCR-free survival rates were $79.2 \%, 75.3 \%$, and $70.2 \%$, respectively [9]. 250 cases have become a landmark for lowest positive surgical margin rates [9].

Increasingly complex cases can be taken on as the learning curve progress [10]. Very often with salvage cases, significant intra-abdominal adhesions, dense per prostatic inflammation post URP; large prostate gland size and median lobes may alter bladder neck anatomy. This makes for a difficult urethra vesicle anastomosis [10]. This highlights the importance of taking on no salvage cases unless at least 200 cases have been completed. 
Compared to open and laparoscopic procedures peri operative sralp outcomes were positive, with low complication rates and estimated blood loss equivocal to open or lap procedures [11]. This demonstrates robotic technology can aid the surgeon in salvage prostatectomy [11]. However, experience and training are key to minimal morbidity [12]. This procedure has significant advantages over open surgery in selected patients and is an excellent alternative to other salvage therapies, and allows a broader spectrum of patients to be treated compared to open surgery [12].Sralp also offers complete staging of high-risk prostate cancer thereby allowing optimum planning of adjuvant and salvage therapies [13]. However, many high-risk prostate cancers are subsequently downgraded or down staged on final histopathology [14], rendering the patient disease free.

However, sralp is technically demanding, and experienced surgeons are needed [15]. Post radiation cystitis, fibrosis, and tissue plane obliteration can lead to significant complications, such as rectal injuries, anastomotic stricture, and urinary incontinence [15]. This highlights how functional status of patients before robot-assisted salvage prostatectomy maybe compromised [11]. Three of the six patients had extremely poor sexual function before surgery (EPIC sexual domain $<50$ ), and three-quarters had significant irritative symptoms (mean EPIC urinary irritation score 60.5) [16]. There were no intra operative complications [16]. Of six patients, four [75\%] remain free of disease; however, incontinence and erectile dysfunction were evident in all, to some degree [16]. Sralp for high risk disease, gives good outcomes both ontologically and functionally, however, good fellowship training and experienced surgeons are key.

\section{References}

1. Wetherell D, Bolton D, Kavanagh L, Perera M (2013) Current role of salvage robotic-assisted laparoscopic prostatectomy. World Journal of Urology 31(3): 463-469.

2. Kaffenberger S, Smith J (2014) Salvage robotic radical prostatectomy. Indian Journal of Urology 30(4): 429-433.

3. Bates AS, Samavedi S, Kumar A, Mouraviev V, Rocco B, et al. (2015) Salvage robot assisted radical prostatectomy: A propensity matched study of perioperative, oncological and functional outcomes. European Journal of Surgical Oncology 41(11): 1540-1546.

4. Eldred Evans D, Sturch P, Cahill D, Dasgupta P, Challacombe B, et al. (2013) Salvage robotic-assisted radical prostatectomy: Challenges and solutions. Urology 1: S170.

5. Diaz M, Peabody JO, Kapoor V, Sammon J, Rogers CG, et al. Oncologic outcomes at 10 years following robotic radical prostatectomy. European Urology 67(6): 1168-1176.

6. Ou YC, Yang CK, Chang KS, Wang J, Hung SW, et al. (2014) The surgical learning curve for robotic-assisted laparoscopic radical prostatectomy: Experience of a single surgeon with 500 cases in Taiwan, China. Asian Journal of Andrology 16(5): 728-734.

7. Zugor V, Labanaris AP, Witt JH (2011) Robotic-assisted salvage prostatectomy Surgical, oncologic and functional outcomes. Urologe Ausgabe A 50: 26.

8. Goldstraw MA, Challacombe BJ, Patil K, Amoroso P, Dasgupta P, et al. Overcoming the challenges of robot-assisted radical prostatectomy. Prostate Cancer and Prostatic Diseases 15(1): 1-7.

9. Murphy D (2012) State of the art lecture 9-the contemporary role of surgery in the management of high-risk prostate cancer. International Journal of Urology 19: 229.

10. Rocco B, Cozzi G, Spinelli MG, Grasso A, Varisco D, et al. (2012) Current status of salvage robot-assisted laparoscopic prostatectomy for radiorecurrent prostate cancer. Current Urology Reports 13(3): 195201.

11. Strope SA, Coelho M, Wood DP, Hollenbeck BK (2010) Robot-assisted salvage prostatectomy: evaluation of initial patient-reported outcomes. Journal of Endourology 24(3): 425-427.

12. Eandi JA, Link BA, Nelson RA, Josephson DY, Lau C, et al. (2010) Robotic Assisted Laparoscopic Salvage Prostatectomy for Radiation Resistant Prostate Cancer. Journal of Urology 183(1): 133-137.

13. Coelho R, Chauhan S, Orvieto M, Patel M, Liss M, et al. (2010) Salvage RALP for radio-recurrent prostate cancer: Description of technique and multi-institutional outcomes. Journal of Urology 183(4): 186.

14. Davis JW, Shah J, Achim M (2010) High risk prostate cancer selected for robot-assisted radical prostatectomy: Surgical planning with image guidance. Journal of Endourology 24: A88-A89.

15. Acar O, Esen T (2014) Robotic radical prostatectomy in patients with previous prostate surgery and radiotherapy. Prostate Cancer 367675.

16. Williams SB, Hu JC (2013) Salvage robotic assisted laparoscopic radical prostatectomy: Indications and outcomes. World Journal of Urology 31(3): 431-434. 